\title{
Genome assembly and methylome analysis of the white wax scale insect provides insight into sexual differentiation of metamorphosis in hexapods
}

\author{
Hang Chen ${ }^{1}$, Qin Lu ${ }^{1}$, Xiaoming Chen ${ }^{1}$, Xiaofei Ling ${ }^{1}$, Pengfei Liu ${ }^{1}$, Ni Liu ${ }^{1}$, Weiwei \\ Wang $^{1}$, Jinwen Zhang ${ }^{1}$, Qian Qi $^{1}$, Weifeng Ding ${ }^{1}$, Xin Zhang ${ }^{1}$, Ying Feng ${ }^{1}$, Yurong Zhang ${ }^{2}$, \\ Ming-Shun $\mathrm{Chen}^{3}$, and Kirst King-jones ${ }^{4}$ \\ ${ }^{1}$ Research Institute of Resource Insects, Chinese Academy of Forestry \\ ${ }^{2}$ Hunan Academy of Forestry \\ ${ }^{3}$ Kansas State University \\ ${ }^{4}$ University of Alberta
}

January 27, 2021

\begin{abstract}
Scale insects are hemimetabolous, showing "incomplete" metamorphosis and no true pupal stage. Ericerus pela, commonly known as the white wax scale insect (hereafter, WWS), is a wax-producing insect found in Asia and Europe. WWS displays dramatic sexual dimorphism, with notably different metamorphic fates in males and females. Males develop into winged adults, while females are neotenic and maintain a nymph-like appearance, which are flightless and remain stationary. Here we report the de novo assembly of the WWS genome with its size of $638.30 \mathrm{Mb}(69.68 \mathrm{Mb}$ for scaffold N50) by PacBio sequencing and Hi-C. From these data, we constructed a robust phylogenetic analysis of 24,923 gene families from 16 representative insect genomes, which indicates that holometabola evolved from incomplete metamorphosis insects in the Late Carboniferous, about 50 million years earlier than previously thought. To study the distinct development of males and females, we analyzed the methylome landscape in either sex. Surprisingly, WWS displayed high levels of methylation (4.42\% for males) when compared to other insects. We observed differential methylation patterns for genes involved in steroid and sesquiterpenoids production as well as related fatty acid metabolism pathways. We show here that both males and females exhibit distinct titer profiles for ecdysone, the principal insect steroid hormone, and juvenile hormone (a sesquiterpenoid), suggesting that these hormones are the primary drivers of sexually dimorphic features. Our results provide a comprehensive genomic and epigenomic resource of scale insects that provide new insights into the evolution of metamorphosis and sexual dimorphism in insects.
\end{abstract}

\section{Hosted file}

Manuscript_genome_WWS-revised.pdf available at https://authorea.com/users/375617/articles/ 506120-genome-assembly-and-methylome-analysis-of-the-white-wax-scale-insect-providesinsight-into-sexual-differentiation-of-metamorphosis-in-hexapods 

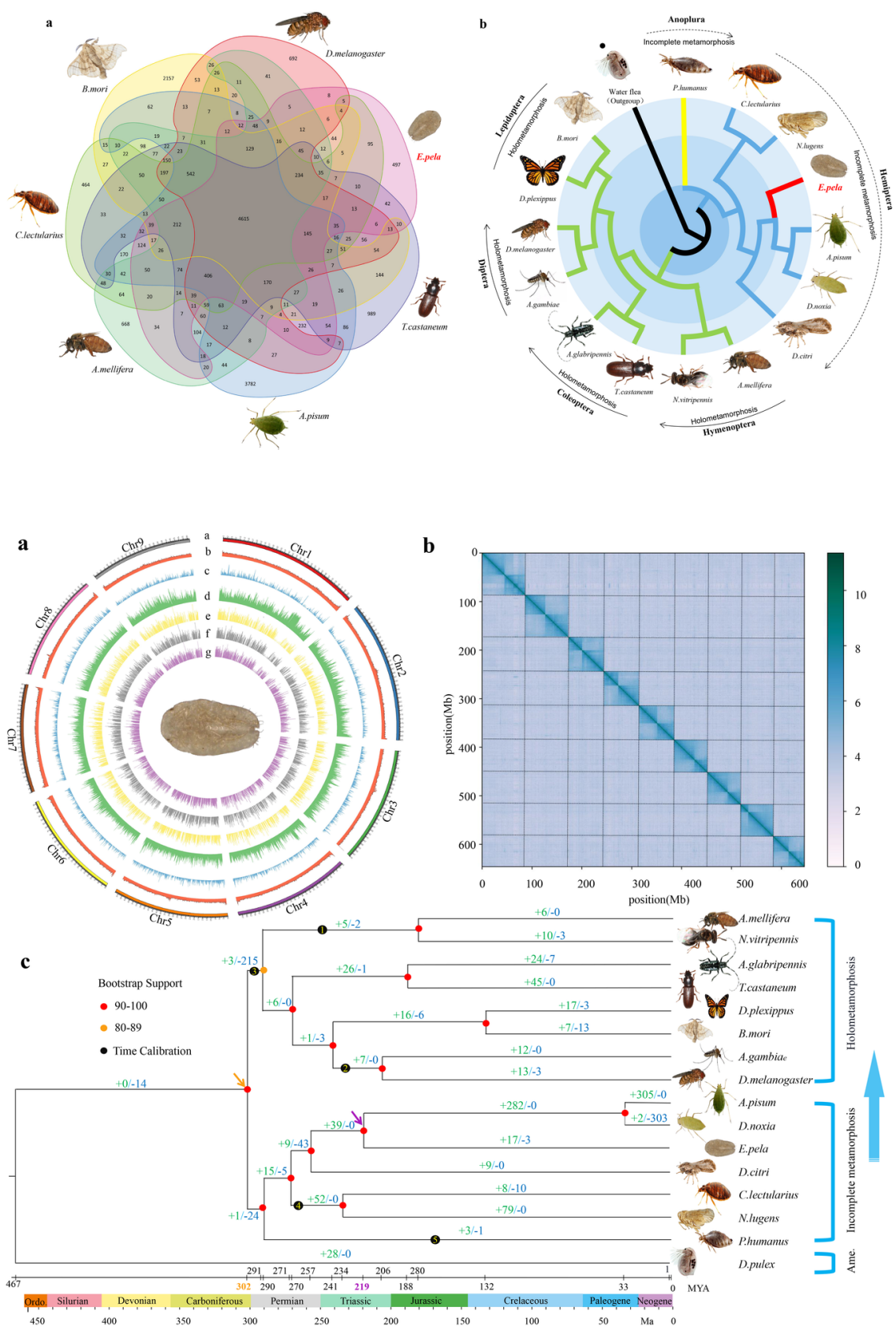

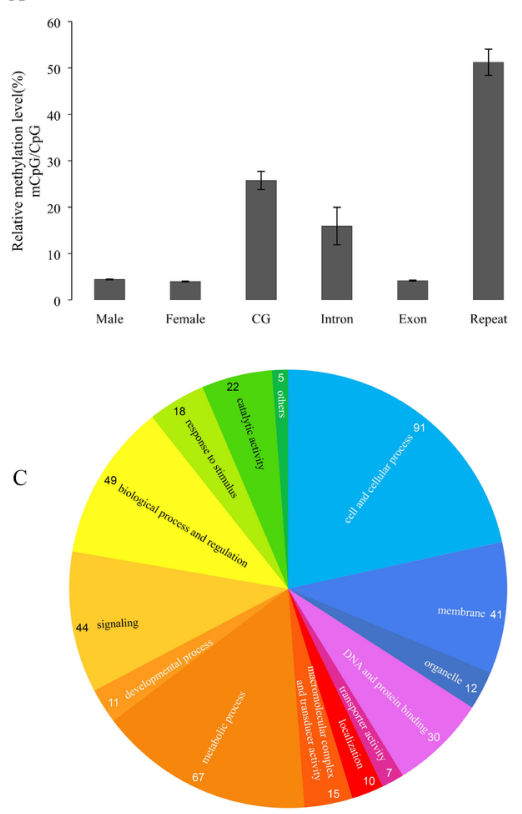

B

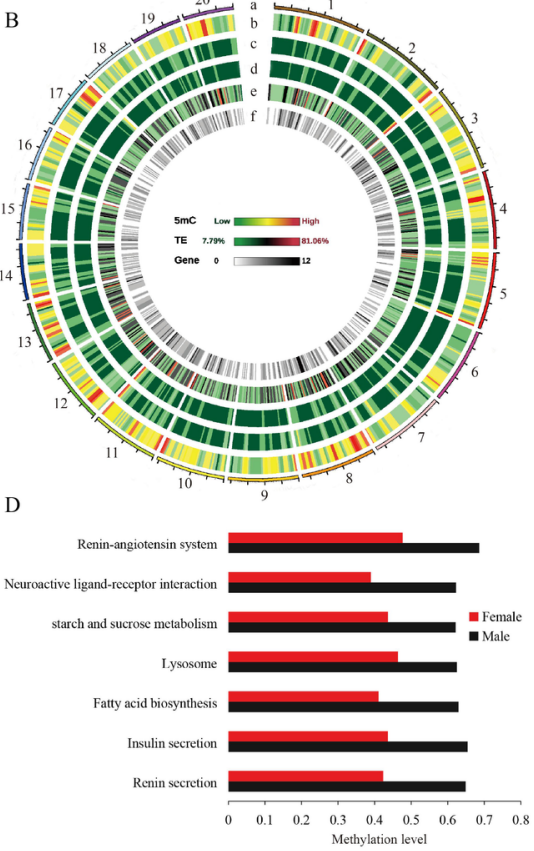


a

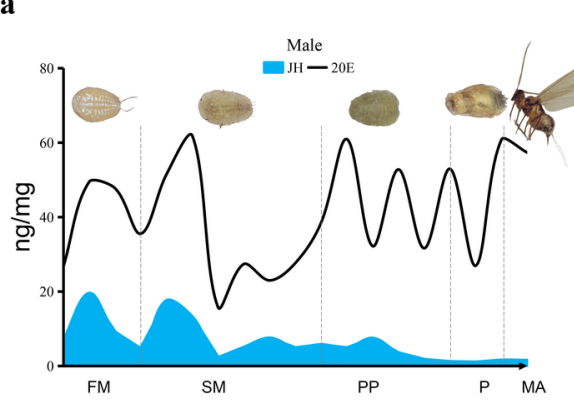

c

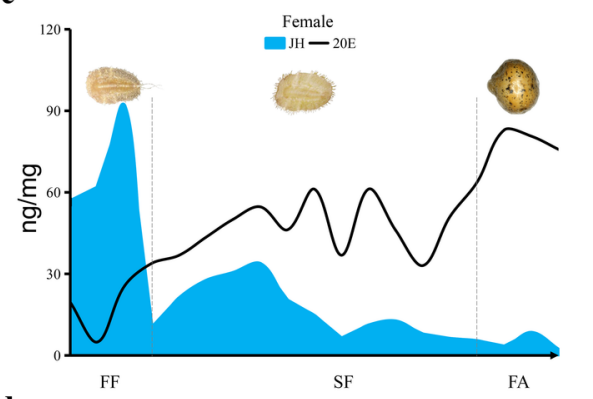

d

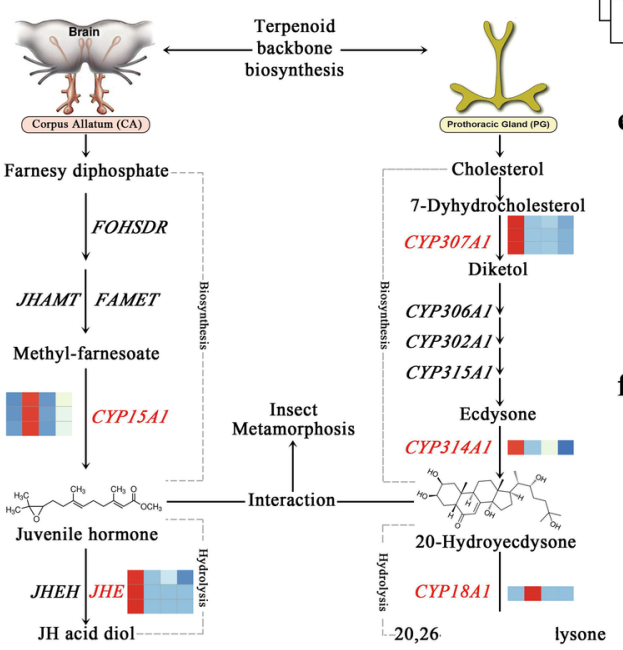

g

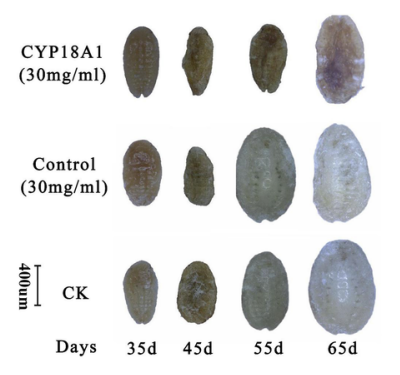

b

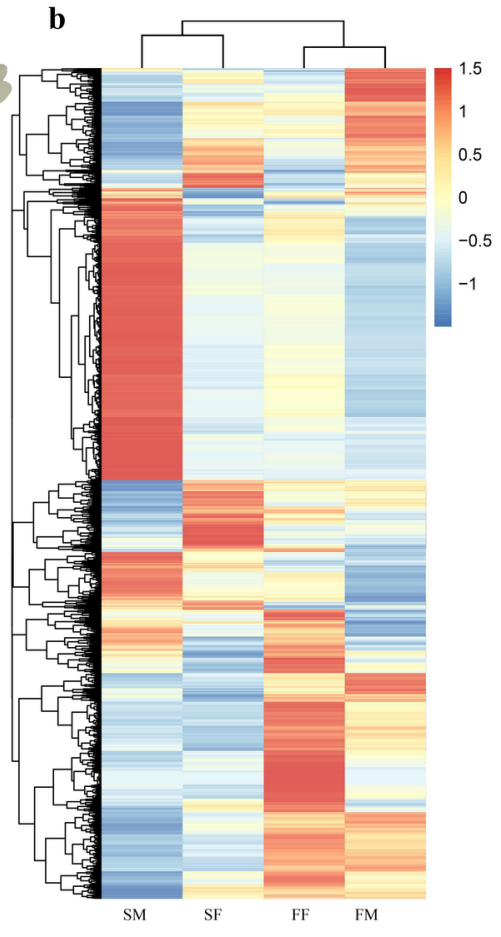

e

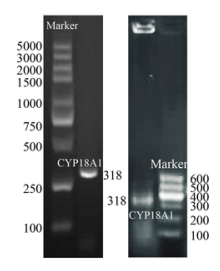

f

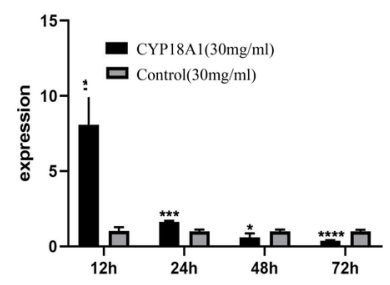

h

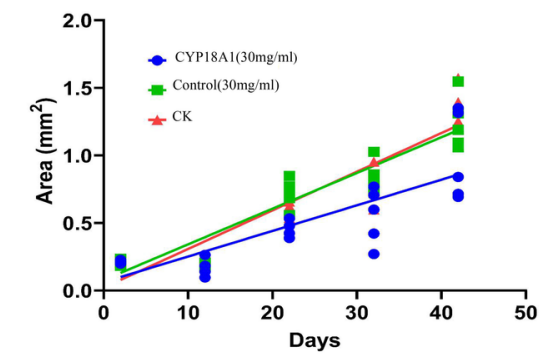

\section{Hosted file}

Table 1.pdf available at https://authorea.com/users/375617/articles/506120-genome-assemblyand-methylome-analysis-of-the-white-wax-scale-insect-provides-insight-into-sexual- 
differentiation-of-metamorphosis-in-hexapods 